\title{
HIV treatment engagement in the context of COVID-19: an observational global sample of transgender and nonbinary people living with HIV
}

Arjee Javellana Restar ${ }^{1 *}$, Henri M. Garrison-Desany ${ }^{1}$, Tyler Adamson $^{2}$, Chase Childress ${ }^{3}$, Gregorio Millett ${ }^{4}$, Brooke A. Jarrett', Sean Howell ${ }^{5}$, Jennifer L. Glick ${ }^{6}$, S. Wilson Beckham ${ }^{6,7}$ and Stefan Baral ${ }^{1}$

\begin{abstract}
Background: HIV services, like many medical services, have been disrupted by the COVID-19 pandemic. However, there are limited data on the impacts of the COVID-19 pandemic on HIV treatment engagement outcomes among transgender (trans) and nonbinary people. This study addresses a pressing knowledge gap and is important in its global scope, its use of technology for recruitment, and focus on transgender people living with HIV. The objective of this study is to examine correlates of HIV infection and HIV treatment engagement outcomes (i.e., currently on ART, having an HIV provider, having access to HIV treatment without burden, and remote refills) since the COVID-19 pandemic began.
\end{abstract}

Methods: We utilized observational data from the Global COVID-19 Disparities Survey 2020, an online study that globally sampled trans and nonbinary people $(n=902)$ between April and August 2020. We conducted a series of multivariable logistic regressions with lasso selection to explore correlates of HIV treatment engagement outcomes in the context of COVID-19.

Results: Of the 120 (13.3\%) trans and nonbinary people living with HIV in this survey, the majority (85.8\%) were currently on HIV treatment. A smaller proportion (69.2\%) reported having access to an HIV provider since COVID-19 control measures were implemented. Less than half reported being able to access treatment without burdens related to COVID-19 (48.3\%) and having the ability to remotely refill HIV prescription (44.2\%). After adjusting for gender in the multivariable models, younger age and anticipated job loss were significantly associated with not having access to HIV treatment without burden. Outcomes also significantly varied by geographic region, with respondents reporting less access to an HIV provider in nearly every region outside of South-East Asia.

* Correspondence: arestar1@jhmi.edu

'Department of Epidemiology, Johns Hopkins School of Public Health, $615 \mathrm{~N}$ Wolfe St, Baltimore, MD 21205, USA

Full list of author information is available at the end of the article

(c) The Author(s). 2021 Open Access This article is licensed under a Creative Commons Attribution 4.0 International License, which permits use, sharing, adaptation, distribution and reproduction in any medium or format, as long as you give appropriate credit to the original author(s) and the source, provide a link to the Creative Commons licence, and indicate if changes were made. The images or other third party material in this article are included in the article's Creative Commons licence, unless indicated otherwise in a credit line to the material. If material is not included in the article's Creative Commons licence and your intended use is not permitted by statutory regulation or exceeds the permitted use, you will need to obtain permission directly from the copyright holder. To view a copy of this licence, visit http://creativecommons.org/licenses/by/4.0/. The Creative Commons Public Domain Dedication waiver (http://creativecommons.org/publicdomain/zero/1.0/) applies to the data made available in this article, unless otherwise stated in a credit line to the data. 


\begin{abstract}
(Continued from previous page)
Conclusion: Our results suggest that currently taking ART, having access to an HIV provider, and being able to access HIV treatment without burden and remotely refill HIV medication are suboptimal among trans and nonbinary people living with HIV across the world. Strengthening support for HIV programs that are well-connected to trans and nonbinary communities, increasing remote access to HIV providers and prescription refills, and providing socioeconomic support could significantly improve HIV engagement in trans and nonbinary communities.
\end{abstract}

Keywords: Coronavirus, COVID-19, Transgender people living with HIV, HIV

\section{Introduction}

The novel coronavirus disease (COVID-19) continues to ravage communities around the world, impacting all areas of life. As of April 24, 2021, SARS-CoV-2 has infected over 137 million people and led to nearly 2.9 million deaths [1]. To mitigate the impact, countries have relied on a range of measures, including closures of schools and businesses, limits on gatherings, border closures, and lockdowns [2]. These measures have unintentionally upended healthcare systems, leading to reductions in access to care, cancellations of elective/ non-emergency surgeries, and rising levels of adverse mental health conditions [3-5]. Of particular concern are impacts to already marginalized communities and an exacerbation of existing health inequities. A growing body of research highlights the barriers to care that transgender (trans) and nonbinary individuals experience as a result of stigma, discrimination, and minority stress [6-8]. Yet there remains a gap in knowledge about how these barriers have evolved within the context of COVID-19.

Trans and nonbinary individuals already face heightened barriers to care, such as a limited number of providers, widespread transphobia among staff, or lack of adequate provider-focused training in working with trans and nonbinary individuals [9-11]. Furthermore, such experiences of care have a direct impact on prescribed treatment, adherence, and impacts to mental health, particularly within the context of HIV and among trans and nonbinary people living with HIV [12-14]. Additionally, the health needs of trans and nonbinary individuals are often forgotten or neglected in disaster relief responses, which can lead to an increase in negative, population-level health outcomes [15].

Structural barriers, coupled with the unprecedented nature of the COVID-19 pandemic, will likely leave this community uniquely vulnerable to disrupted engagement in HIV treatment and requires a targeted and tailored approach to address such vulnerability going forward $[4,5,16]$. Given the evolving and unknown nature of this virus, there have been coordinated efforts to prioritize individuals with preexisting conditions, compromised immune systems, and high risk of illness or death [3, 17-19]. However, previous research has shown that amid similar disasters, there are also interruptions to HIV care and engagement [20]. While there has been a proliferation of research on the ramifications of COVID-19 among those living with HIV $[3,5]$, little, if any, has been dedicated to documenting engagement in HIV treatment among trans and nonbinary individuals in the context of COVID-19. This is despite the widespread acknowledgment that globally, trans and nonbinary people are considered a key population in HIV mitigation and are particularly vulnerable to loss of care $[21,22]$.

In order to mitigate the impacts of COVID-19 on HIV treatment engagement for trans and nonbinary individuals, it is imperative to characterize and understand the extent to which access to HIV treatment has been impacted. Drawing on lessons learned from the HIV epidemic [23], this study sought to characterize the impact of COVID-19 on HIV treatment engagement among trans and nonbinary individuals living with HIV around the world. We also examined differences in HIV status, and treatment and engagement-related outcomes (e.g., currently on ART, having an HIV provider, having access to HIV treatment without burden, and access to remote refills) across geographic regions, socioeconomic status, and employment.

\section{Methods \\ Study sample, procedures, and design}

For best-practice reporting of cross-sectional study design, we utilized the STROBE checklist (Supplemental, Supporting Checklist).

This is a secondary analysis of data from the Global COVID-19 Disparities Survey 2020, a study that examined the impact of the COVID-19 pandemic on trans and nonbinary wellbeing among social networking applications (apps) members. This study specifically focuses on trans and nonbinary people's HIV status and treatment and engagement-related outcomes such as currently on ART, having an HIV provider, having access to HIV treatment without burden, and remote refills. Study procedures have been reported elsewhere [24]. In brief, participants were recruited online via "Hornet" and 
"Her" social networking/dating apps. Survey invitations were sent out to app members who used their apps in the past year. Participants were screened for eligibility and were eligible if they are: (1) at least 18 years old, (2) an app member, and (3) provided electronic consent.

We utilized best-practice approaches to maximize data quality and reduce information bias, including a deduplication process via (1) removal of any non-unique IP addresses, and (2) a cross-matching process that flags identical responses to 20 random variables. Other approaches included removing participants with incomplete responses (i.e., completed less than $90 \%$ of the survey), response time below the piloted time of 7 mins, illogical responses, and those with no HIV status data.

\section{Ethics}

The Johns Hopkins School of Public Health Institutional Review Board reviewed and approved this study (IRB \#00000287). All enrolled participants provided electronic informed consent and consent for publication.

\section{Measures and analyses}

We included variables in this analysis based on previous research $[9-11,22]$ and within the parameters of measures that were available in the secondary dataset (Supplemental, Survey Questionnaire). We compared demographics (i.e., gender identity, age, education, socioeconomic status, migrant status, region of residence according to the World Health Organization (WHO) definition [25], urban/rural setting, and racial/ethnic minority status) and socio-economic loss due to COVID-19 pandemic (e.g., anticipated income reduction, anticipated insurance loss, anticipated job loss/unemployment, cutting meals) by HIV status. We then compared demographics and socioeconomic loss due to the COVID-19 pandemic among HIV-positive trans and nonbinary people who were currently on ART, had an HIV provider, had access to HIV treatment without burden, and had remote refills since the COVID-19 pandemic began.

Bivariate analyses were conducted using $X^{2}$ or Fisher's Exact tests appropriately to describe relationships of the independent variables, stratified by HIV status. A series of multivariable regressions was used to build each model per outcome (e.g., currently on ART, having an HIV provider, having access to HIV treatment without burden, and remote refills). Given the exploratory nature of this study, prior to analysis, we utilized lasso to select the key variables to include in the model [26]. All of the variables that were selected by the lasso procedure were included per model. Additionally, given our modest sample size, we utilized a nonparametric bootstrapping procedure with 1000 iterations to strengthen our confidence intervals and reduce Type 1 error for each of our model
[27]. Following guidelines from Restar and colleagues [28], we utilized a gender-inclusive approach to the analysis - that is, given that no significant differences were found between HIV status and gender, we did not analyze each model by gender in separate analysis but instead analyzed the entire sample while controlling for gender identity in all of the adjusted multivariable models. Lastly, we noted which variables were considered to be significant at $p<0.05$. All analyses were performed using StataSE version 16.1.

\section{Results}

\section{Sample characteristics}

Initially, the survey had 4031 responses which, following data quality processing, resulted in an overall sample of 3139. For this analysis, we further limited our sample to only participants who identified as transgender or nonbinary, resulting in a final sample of 902 participants. Table 1 shows an overview of demographic and socioeconomic characteristics of the sample by HIV status. Overall, a total of $64.4 \%$ of trans and nonbinary people in this sample reported their HIV status as negative, $13.3 \%$ as positive, and $21.3 \%$ as unknown. Among those who reported their HIV status as positive $(n=120)$, $72.5 \%$ identified as nonbinary, $4.2 \%$ trans masculine, and $23.3 \%$ trans feminine. Additionally, among nonbinary respondents who participated in the study, a total of $14.4 \%$ (87/604) reported living with HIV compared to $14.2 \%$ (5/35) trans masculine and $10.6 \%(28 / 263)$ trans feminine people reported living with HIV.

A majority of the sample identified their gender as nonbinary $(67.0 \%)$, followed by trans feminine (29.2\%) and trans masculine (3.8\%). Half the sample were participants between ages 18-29 years old (51.3\%), had attained some college education (76.2\%), and were from lower-middle (49.5\%) and upper-middle (30.3\%) socioeconomic status. A total of $15.2 \%$ identified as migrants. Most of the sample were from European (48.3\%) and South-East Asian WHO regions (24.7\%), and a majority (71.1\%) were residing in urban areas. More than a quarter $(26.4 \%)$ identified as $\mathrm{racial} / \mathrm{ethnic}$ minorities. Additionally, $72.9 \%$ of the sample anticipated income reduction, $38.5 \%$ anticipated insurance loss, $15.8 \%$ anticipated job loss/unemployment, and $39.6 \%$ had cut meals. Level of socioeconomic status, WHO region, urban/rural setting, racial/ethnic minority, anticipated income reduction, and anticipated insurance loss were independently associated with HIV status.

\section{HIV treatment and access engagement}

Figure 1 displays HIV treatment and access engagement outcomes. Among trans and nonbinary people in this sample who reported living with HIV (13.3\%), the majority $(85.8 \%)$ were currently on treatment. A smaller 
Table 1 Sample demographics and socio-economic loss impact characteristics by HIV status in a global sample of transgender and nonbinary people $(n=902)$

\begin{tabular}{lllll}
\hline & $\begin{array}{l}\text { Total } \\
\mathbf{n}(\%)\end{array}$ & $\begin{array}{l}\text { HIV-negative } \\
\mathbf{n}(\%)\end{array}$ & $\begin{array}{l}\text { HIV-positive } \\
\mathbf{n}(\%)\end{array}$ & $\begin{array}{l}\text { HIV-unknown } \\
\mathbf{n}(\%)\end{array}$ \\
\hline Total & $902(100.00)$ & $590(64.41)$ & $120(13.30)$ & $192(21.29)$
\end{tabular}

\section{Demographics}

Gender identity

Nonbinary

Trans masculine

Trans feminine

Age

18-29years old

30-39 years old

40-29 years old

50 or more years old

Education

Less than college

College/Some college

$213(23.83)$

$681(76.17)$

Level of socioeconomic status

Lower
Lower-middle
Upper-middle
Upper
Migrant status
No/Unsure
Yes

141 (15.68)

$445(49.50)$

$272(30.26)$

$41(4.56)$

$754(84.81)$

$135(15.19)$

WHO continent region

South-East Asia

$217(24.72)$

$83(9.45)$

Americas

Eastern Mediterranean

$80(9.11)$

Africa

34 (3.87)

Europe

$424(48.29)$

Western Pacific

$40(4.56)$

658 (71.11)

$242(26.89)$

Racial/Ethnic Minority
$662(73.64)$
$237(26.36)$
No/Not Sure
Yes

Socio-economic Loss due to COVID-19 Indicators

Income reduction (anticipated)

No

Yes

Insurance loss (anticipated)

No
239 (27.10)

$643(72.90)$

$382(61.51)$

$239(38.49)$
391 (66.27)

$22(3.73)$

$177(30.00)$

$308(52.20)$

$170(28.81)$

$78(13.22)$

$34(5.76)$

137 (23.30)

$451(76.70)$

$87(14.77)$

$277(47.03)$

$195(33.11)$

30 (5.09)

$482(83.10)$

98 (16.90)

$124(21.60)$

61 (10.63)

64 (11.15)

22 (3.83)

277 (48.26)

26 (4.53)

449 (76.36)

139 (23.64)

87 (72.50)

5 (4.17)

$28(23.33)$

57 (47.50)

39 (32.50)

13 (10.83)

11 (9.17)

28 (23.73)

90 (76.27)

19 (15.97)

69 (57.98)

23 (19.33)

8 (6.72)

104 (86.67)

16 (13.33)

$36(30.51)$

$14(11.86)$

9 (7.63)

9 (7.63)

48 (40.68)

2 (1.69)

85 (70.83)

35 (29.17)

425 (72.16)

164 (27.84)

82 (68.91)

37 (31.09)

21 (17.65)

98 (82.35)

265 (64.79)

144 (35.21)

167 (28.99)

43 (49.43)

$44(50.57)$
126 (65.62)

$0.642^{f}$

8 (4.17)

58 (30.21)

98 (51.04)

0.558

58 (30.21)

28 (14.58)

8 (4.17)

48 (25.53)

0.822

140 (74.47)

35 (18.35)

$0.010^{f}$

99 (51.83)

54 (28.27)

$3(1.57)$

168 (88.89)

0.130

21 (11.11)

57 (30.65)

$<0.001$

8 (4.30)

7 (3.76)

$3(1.61)$

99 (53.23)

12 (6.45)

124 (64.58)

0.005

68 (35.42)

155 (81.15)

0.022

36 (18.85)

51 (27.27)

0.040

136 (72.73)

74 (59.20)

0.023

51 (40.80) 
Table 1 Sample demographics and socio-economic loss impact characteristics by HIV status in a global sample of transgender and nonbinary people $(n=902)$ (Continued)

\begin{tabular}{|c|c|c|c|c|c|}
\hline & $\begin{array}{l}\text { Total } \\
\text { n (\%) }\end{array}$ & $\begin{array}{l}\text { HIV-negative } \\
\text { n (\%) }\end{array}$ & $\begin{array}{l}\text { HIV-positive } \\
\text { n (\%) }\end{array}$ & $\begin{array}{l}\text { HIV-unknown } \\
\text { n (\%) }\end{array}$ & $p$-value \\
\hline \multicolumn{6}{|c|}{ Job loss/unemployment (anticipated) } \\
\hline No & $753(84.23)$ & $502(86.11)$ & $97(80.83)$ & $154(80.63)$ & 0.104 \\
\hline Yes & $141(15.77)$ & $81(13.89)$ & $23(19.17)$ & 37 (19.37) & \\
\hline \multicolumn{6}{|c|}{ Cutting Meals } \\
\hline No & $510(60.36)$ & $345(61.61)$ & $61(54.46)$ & $104(60.12)$ & 0.369 \\
\hline Yes & 335 (39.64) & 215 (38.39) & $51(45.54)$ & 69 (39.88) & \\
\hline
\end{tabular}

${ }^{\mathrm{f}}$ Fisher Exact Test. Column percentages are reported. Sample sizes stratified by variables may not add up to total sample size due to missingness

proportion (69.2\%) reported having access to an HIV provider since pandemic control measures were implemented. Similarly, less than half reported being able to access treatment without burdens related to COVID-19 (48.3\%) and being able to refill their prescription remotely (44.2\%).

\section{Multivariable logistic regression analyses of HIV} treatment and access engagement outcomes

Table 2 displays the results of final adjusted multivariable logistic regressions with lasso variable selection per HIV treatment engagement outcome. Specifically, the first adjusted regression model (outcome: current HIV treatment) included the following variables: gender identity, age, education, level of socioeconomic status, and region. The second adjusted regression model (outcome: access to HIV provider) included gender identity, age, region, and anticipated job loss/unemployment. The third adjusted regression model (outcome: access to treatment) included gender identity, age, education level of socioeconomic status, migrant status, region, anticipated income reduction, anticipated job loss/unemployment, and having cut meals. And lastly, the fourth adjusted regression model (outcome: remote prescription refill) included gender identity and level of socioeconomic status.

In the final regression model (current HIV treatment), trans masculine people living with HIV had lower odds of being on current HIV treatment (adjusted odds ratio $[\mathrm{aOR}]=0.55,95 \%$ Confidence Interval $[\mathrm{CI}]=0.34-0.90$ ) compared to nonbinary people living with HIV. Moreover, trans and nonbinary people living with HIV who attained some college education had higher odds of being on current HIV treatment compared to those with less than college education.

Moreover, trans and nonbinary people living with HIV between ages $40-49$ years old $(\mathrm{aOR}=1.29,95 \% \mathrm{CI}=$ $1.01-1.64)$ and 50 or more years old $(\mathrm{aOR}=1.30$, $95 \% \mathrm{CI}=1.02-1.65)$ had higher odds of having access to an HIV provider compared to those between 18 and 29

\section{HIV Treatment Engagement since COVID-19 pandemic began among Transgender and Nonbinary People Living with HIV ( $n=120)$}
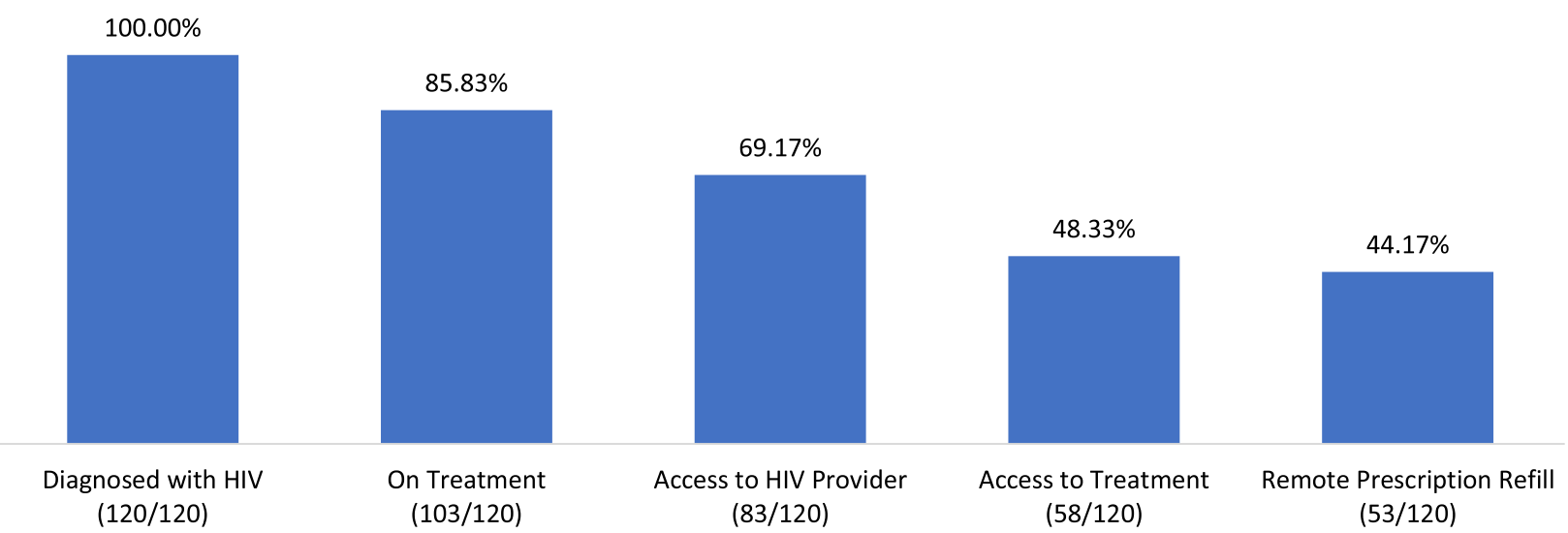

- Participants reporting outcome

Fig. 1 HIV treatment engagement since COVID-19 pandemic began among transgender and nonbinary people living with HIV 
Table 2 Results of adjusted multivariable logistic regression with lasso variable selection: Correlates of HIV treatment engagement in the context of COVID-19 in a global sample of transgender and nonbinary people living with HIV

\begin{tabular}{|c|c|c|c|}
\hline HIV treatment engagement outcomes & Lasso-selected factors & Adjusted OR $(95 \% \mathrm{Cl})$ & $p$-value \\
\hline \multicolumn{4}{|l|}{ On treatment } \\
\hline & Gender identity & & \\
\hline & Nonbinary & ref & \\
\hline & Trans masculine & $0.55(0.34-0.90)^{*}$ & 0.018 \\
\hline & Trans feminine & $0.88(0.72-1.07)$ & 0.229 \\
\hline & Age & & \\
\hline & $18-29$ years old & ref & \\
\hline & $30-39$ years old & $1.07(0.92-1.23)$ & 0.345 \\
\hline & 40-29 years old & $1.04(0.85-1.28)$ & 0.649 \\
\hline & 50 or more years old & $0.97(0.68-1.37)$ & 0.866 \\
\hline & Education & & \\
\hline & Less than college & ref & \\
\hline & College/Some college & $1.27(1.02-1.59)^{*}$ & 0.033 \\
\hline & Level of socioeconomic status & & \\
\hline & Lower & ref & \\
\hline & Lower-middle & $0.90(0.63-1.29)$ & 0.593 \\
\hline & Upper-middle & $0.84(0.56-1.26)$ & 0.413 \\
\hline & Upper & $0.83(0.41-1.65)$ & 0.603 \\
\hline & WHO continent region & & \\
\hline & South-East Asia & & \\
\hline & Americas & $1.01(0.83-1.23)$ & 0.854 \\
\hline & Eastern Mediterranean & $0.90(0.73-1.10)$ & 0.325 \\
\hline & Africa & $1.23(0.98-1.53)$ & 0.062 \\
\hline & Europe & $0.84(0.61-1.16)$ & 0.300 \\
\hline & Western Pacific & $0.85(0.48-1.48)$ & 0.570 \\
\hline \multicolumn{4}{|l|}{ Access to HIV Provider } \\
\hline & Gender identity & & \\
\hline & Nonbinary & ref & \\
\hline & Trans masculine & $0.89(0.46-1.72)$ & 0.748 \\
\hline & Trans feminine & $0.94(0.75-1.18)$ & 0.637 \\
\hline & Age & & \\
\hline & $18-29$ years old & ref & \\
\hline & 30-39 years old & $1.19(0.97-1.45)$ & 0.089 \\
\hline & 40-49 years old & $1.29(1.01-1.64)^{*}$ & 0.036 \\
\hline & 50 or more years old & $1.30(1.02-1.65)^{*}$ & 0.031 \\
\hline & WHO continent region & & \\
\hline & South-East Asia & ref & \\
\hline & Americas & $0.65(0.49-0.86)^{*}$ & 0.002 \\
\hline & Eastern Mediterranean & $0.85(0.56-1.30)$ & 0.475 \\
\hline & Africa & $0.65(0.44-0.96)^{*}$ & 0.035 \\
\hline & Europe & $0.78(0.63-0.92)^{*}$ & 0.006 \\
\hline & Western Pacific & $0.37(0.29-0.46)^{*}$ & $<0.001$ \\
\hline & Job loss/unemployment (anticipated) & & \\
\hline & No & ref & \\
\hline & Yes & $1.11(0.91-1.34)$ & 0.292 \\
\hline
\end{tabular}


Table 2 Results of adjusted multivariable logistic regression with lasso variable selection: Correlates of HIV treatment engagement in the context of COVID-19 in a global sample of transgender and nonbinary people living with HIV (Continued)

\begin{tabular}{|c|c|c|c|}
\hline HIV treatment engagement outcomes & Lasso-selected factors & Adjusted OR (95\% Cl) & $p$-value \\
\hline \multicolumn{4}{|l|}{ Access to Treatment } \\
\hline & Gender identity & & \\
\hline & Nonbinary & ref & \\
\hline & Trans masculine & $0.88(0.60-1.30)$ & 0.548 \\
\hline & Trans feminine & $0.87(0.72-1.06)$ & 0.179 \\
\hline & Age & & \\
\hline & 18-29 years old & ref & \\
\hline & 30-39 years old & $1.36(1.01-1.84)^{*}$ & 0.041 \\
\hline & 40-29 years old & $1.63(1.17-2.26)^{*}$ & 0.003 \\
\hline & 50 or more years old & $1.31(1.03-1.67)^{*}$ & 0.026 \\
\hline & Education & & \\
\hline & Less than college & ref & \\
\hline & College/Some college & $0.97(0.86-1.08)$ & 0.622 \\
\hline & Level of socioeconomic status & & \\
\hline & Lower & ref & \\
\hline & Lower-middle & $0.84(0.71-1.01)$ & 0.060 \\
\hline & Upper-middle & $0.99(0.82-1.19)$ & 0.935 \\
\hline & Upper & $0.64(0.47-1.88)$ & 0.065 \\
\hline & Migrant status & & \\
\hline & No/Unsure & ref & \\
\hline & Yes & $0.89(0.72-1.09)$ & 0.279 \\
\hline & WHO continent region & & \\
\hline & South-East Asia & ref & \\
\hline & Americas & $1.30(1.09-1.55)^{*}$ & 0.003 \\
\hline & Eastern Mediterranean & $0.74(0.46-1.18)$ & 0.217 \\
\hline & Africa & $0.90(0.70-1.15)$ & 0.413 \\
\hline & Europe & $0.99(0.82-1.19)$ & 0.924 \\
\hline & Western Pacific & $0.87(0.29-2.58)$ & 0.803 \\
\hline & Income reduction (anticipated) & & \\
\hline & No & ref & \\
\hline & Yes & $1.21(0.87-1.70)$ & 0.247 \\
\hline & Job loss/unemployment (anticipated) & & \\
\hline & No & ref & \\
\hline & Yes & $0.79(0.63-0.90)^{*}$ & 0.044 \\
\hline & Cutting Meals & & \\
\hline & No & ref & \\
\hline & Yes & $0.86(0.71-1.05)$ & 0.167 \\
\hline \multicolumn{4}{|l|}{ Remote Prescription Refill } \\
\hline & Gender identity & & \\
\hline & Nonbinary & ref & \\
\hline & Trans masculine & $1.44(0.96-2.16)$ & 0.075 \\
\hline & Trans feminine & $0.98(0.79-1.23)$ & 0.910 \\
\hline & Level of socioeconomic status & & \\
\hline & Lower & ref & \\
\hline & Lower-middle & $1.13(0.88-1.46)$ & 0.326 \\
\hline & Upper-middle & $1.06(0.77-1.46)$ & 0.708 \\
\hline & Upper & $1.54(1.03-2.30)^{*}$ & 0.033 \\
\hline
\end{tabular}

${ }^{*} p<0.05$, OR odds ratio, 95\% Cl 95\% Confidence Interval, WHO World Health Organization. Each model/outcome ran under a nonparametric bootstrapping procedure with 1000 iterations 
years old. Moreover, trans and nonbinary people living with HIV in the Americas $(\mathrm{aOR}=0.65,95 \% \mathrm{CI}=0.49-$ 0.86 ), Africa $(\mathrm{aOR}=0.65,95 \% \mathrm{CI}=0.44-0.96)$, Europe (aOR $=0.78,95 \% \mathrm{CI}=0.63-0.92)$ and Western Pacific $(\mathrm{aOR}=0.37,95 \% \mathrm{CI}=0.29-0.46)$ had lower odds of accessing an HIV provider since COVID-19 pandemic control measures were implemented compared to those who are living with HIV in the South-East Asia region,

In the final regression model (access to treatment), trans and nonbinary people living with HIV between ages of $30-29$ years old $(\mathrm{aOR}=1.36,95 \% \mathrm{CI}=1.01-1.84)$, $40-49$ years old $(\mathrm{aOR}=1.31,95 \% \mathrm{CI}=1.03-1.67)$, and 50 or more years old $(\mathrm{aOR}=1.63,95 \% \mathrm{CI}=1.17-2.26)$, had higher odds of having access to treatment compared to those between ages 18-29 years old. Compared to those in the South-East Asia region, those residing in the Americas had higher odds of accessing HIV treatment without burdens related to COVID-19 (aOR $=1.30,95 \%$ $\mathrm{CI}=1.09-1.55)$. Moreover, those who anticipated job loss/unemployment had lower odds of accessing HIV treatment without burdens related to COVID-19 compared to those who did not $(\mathrm{aOR}=0.79,95 \% \mathrm{CI}=$ 0.63-0.90).

Finally, the ability to refill HIV prescriptions remotely was significantly higher among those from upper socioeconomic status compared to those from a lower socioeconomic status $(\mathrm{aOR}=1.54,95 \% \mathrm{CI}=1.03-2.30)$.

\section{Discussion}

The results of this observational study reflect the high burden of HIV among the trans and nonbinary community. The majority of participants identified as nonbinary, which is often an understudied portion of the transgender community $[1,2]$ and highlights the novelty of our results. Notably, we found the majority of the sample who anticipated job loss/unemployment had lower odds of accessing HIV treatment without burdens related to COVID-19, and that those with higher socioeconomic status had higher odds of having the ability to refill HIV prescriptions remotely. This pattern suggests significant economic precarity, as well as a general replication of the widening wealth gap among the broader population [29, 30]. Also notable was the difference in odds of accessing an HIV provider and accessing HIV treatment by geographic region since the pandemic began. While trans and nonbinary people living with HIV in South-East Asia had higher odds of accessing HIV treatment relative to those living in the Americas, Africa, Europe and the Western Pacific, those residing in the Americas had higher odds of accessing such treatment without COVID-19 burdens. Similarly, those who are older than the age group 18 to 29 years old report higher access to HIV providers and to HIV treatment, and those who attained college education are more likely to be currently on HIV treatment compared to those with less than college education. These results may partially reflect differing regional responses to the pandemic over time, while also showing that more affluent subgroups of trans and nonbinary populations (e.g., educated, from upper socioeconomic status) have been able to engage and maintain HIV treatment during the pandemic. While more research must be done to confirm these hypotheses, this study lends valuable insight into how COVID-19 restrictions have impacted access to care among this understudied and underserved population across the globe.

This study shows the importance of testing among transgender populations, and the particular nuances related to gender identity and HIV status. Roughly $20 \%$ of our study population did not know their HIV status. While this comports with prior reports of lower testing among transgender populations compared to cisgender populations [3], it is of particular concern given our sample population was recruited from a dating app and are at potentially greater risk than a population-based sample of transgender people [31]. Among those who did know their HIV positive status, a majority (72.5\%) identified as nonbinary people. This further supports recommendations for tailored testing strategies to trans and nonbinary people, in order to more quickly inform individuals of their HIV status and risk.

Moreover, we found that those with higher socioeconomic status had higher odds of being able to refill their prescription remotely while those who anticipated job loss/unemployment had lower odds of accessing HIV treatment without burdens related to COVID-19, which may suggest that the disruptive effects of the pandemic may have been lessened for trans and nonbinary people with greater economic resources than others. This potentially divergent recovery period is in line with other theories of the economic impact of COVID-19 [30]. In the US, for example, there are reports of a widening wealth gap between higher income earners who were able to more seamlessly transition to remote work, while maintaining their income, jobs, and insurance coverage over the period [30]. By extension, income security likely makes it easier to maintain care, including continuing to pay for prescription or accessing care; while individuals in lower socioeconomic status who faced reduced income seemed to struggle to maintain care.

A similar difference in coping is seen geographically. Trans and nonbinary people with HIV in the Americas, Europe, Western Pacific, and Africa had lower odds of accessing a provider or treatment since pandemic control measures were implemented. Because of the crosssectional nature of the data, it is difficult to determine if this is due to regional differences in access to care in general, or to changes in access due to the pandemic. 
Our study sample may have been less likely to access treatment compared to other transgender people due to prior issues preceding the pandemic [32], including lack of transgender-competent providers in their area or reluctance to disclose transgender status to providers and therefore not receiving relevant/tailored care, structural barriers such as lack of income for appointments and medications, lack of transportation to appointments or pharmacies, or experiencing discrimination at appointments. Further research must be done to understand if this reduced average is related to temporal changes in care. Moreover, given that country-level policies and socio-political climates for transgender rights and health vary within a region, it is particularly important to look into country-level analysis and/or region-specific reporting as a point of future research to understand how access to both in primary and specifically transgender care were impacted by COVID-19 among countries with various levels of social and political acceptance of transgender communities.

For instance, if our results reflect healthcare changes specific to the pandemic period, it may reflect challenges that phases of lockdown and financial hardship had on trans and nonbinary people, which differed by WHO region. Comparing the South-East Asian region to the European region and extrapolating the Oxford COVID19 Restriction Tracker [8] to our study period of April to August, the South-East Asian region generally experienced stricter restrictions in the beginning, which eventually gave way to the same or lower levels of restrictions beginning between roughly May or July. Within the European region, there were a greater number of fluctuations in levels of restrictions, with higher levels being implemented early on, their reduction by June and July, and finally an increase in restrictions beginning in September. Differences in respective pandemic responses may have resulted in different disruptions to healthcare [9], where the stop-start nature of some country responses and poor communication about risks may have made it more difficult for trans and nonbinary people to navigate healthcare resources in these regions. In the US, which had such fluctuations, healthcare utilization through August was reduced across nearly all medical specialties, including adult primary care and immunology [10]. This remained true even for telemedicine appointments which would not be burdened by other barriers to care. Further research must be conducted to understand region-specific correlates to treatment access by region.

Other important findings worth noting include differences in HIV treatment engagement outcomes by age and gender. Specifically, we found that trans masculine people who are living with HIV are less likely, compared to nonbinary people, to report being on current HIV treatment. Moreover, younger trans and nonbinary adults were less likely to have access to HIV prevention and treatment compared to older trans and nonbinary adults. These results suggest that there are differences across age and gender identity strata and that there is a need to explore how these results may differ by subgroups globally, given that trans and nonbinary communities are a non-monolithic group [33]. More importantly, these results provide information for current HIV treatment programs operating under COVID pandemic conditions, particularly regarding which subgroups of trans and nonbinary people living with HIV are in need of bolstering outreach strategies. It is critical for HIV/AIDS treatment services to adapt sensitive and tailored trans programming strategies to subgroups of trans and nonbinary populations.

\section{Strengths}

This study had a number of strengths, including its timeliness in the COVID-19 pandemic, and its focus on an often-underrepresented population that is likely more vulnerable to suboptimal HIV treatment engagement risk and socioeconomic burdens from these necessary governmental restrictions. Our data was collected globally from April to August 2020, during early-pandemic restrictions. Given the fast-changing nature of COVID19 prevalence rates and the policy responses from governments, our data represents an important snapshot into how this landscape of restrictions, re-openings, and their socioeconomic and healthcare burden may have impacted trans and nonbinary people's access to HIV treatment across the world. Additionally, our data was comprised of trans and nonbinary people sampled across the globe, particularly those living with HIV. The challenge to identify and enroll trans and nonbinary people in research has been previously described $[12,13]$, and the use of an app-driven sampling scheme, as opposed to sampling based in health systems or physical venues, may reduce selection bias potentially seen in prior studies [14, 15]. Finally, we assessed HIV treatment outcomes that supports delineating steps for HIV treatment engagement to continued medication adherence. In order to ensure eventual medication adherence, understanding these interim steps of care and the reduction in retention is necessary. Without access to medication, no adherence is possible.

\section{Limitations}

This study is not without limitations. First, the crosssectional nature of this study prevents us from inferring the directionality of the associations, as well as general understanding of changes in our outcomes over time. Second, the convenience online sampling approach via mobile apps limits the generalizability of our results and 
is not representative of all trans and nonbinary populations globally, especially those living with HIV who are not on these mobile apps. Third, due to the self-report responses of this survey, outcomes such as HIV status may have been underreported given that HIV is more stigmatized in some areas of the world compared to others [16]. Our study may have benefited from having biomarkers for more objective estimation. Lastly, this analysis used a nonparametric bootstrap procedure to help reduce Type 1 error inflation while making multiple comparisons. While such procedures do not guarantee control of Type 1 error, the goal of this paper was to generate hypotheses for future research and confirmation. Despite these limitations, the Global COVID-19 Disparities Survey 2020 is one of the largest surveys that sample trans and nonbinary populations globally and the survey data provided us with insights into the lives of already marginalized populations at the time of COVID19 pandemic.

\section{Public health implications}

Trans and nonbinary populations around the world continue to be significantly impacted by the COVID-19 pandemic, facing both HIV burden and lack of access to HIV-related treatment and care. This study was able to provide insight into how COVID-19 has impacted HIV treatment engagement in this understudied population. Moreover, given that trans and nonbinary communities bear the brunt of structural inequalities and are marginalized across intersections of racism, sexism, classism, and transphobia, it is critical for policymakers, program designers, and public health stakeholders to center trans and nonbinary populations across policies, health services programming, and COVID disaster-relief programs [34]. Access to remote HIV-related services, such as telehealth and remote prescriptions, were only partially accessible among trans and nonbinary communities across the world. Thus, innovative solutions to access treatment and providers during pandemic-related disruptions are necessary to retain vulnerable populations in care, including: (1) ensuring HIV surveillance systems include trans and nonbinary gender identities, (2) allowing more flexible remote prescription options for HIV medications, (3) mandating insurance policies to increase coverage for access to telehealth service, (4) providing gendersensitivity and -competency trainings for providers on the frontlines of COVID-19 care, in order to reduce potential negative interactions with trans and nonbinary individuals, and (5) equitably allocating funds to support programs and the healthcare workforce providing HIV care for trans and nonbinary populations. This study provides important groundwork for further research and policies that benefit trans and nonbinary people during the COVID-19 pandemic.

\section{Supplementary Information}

The online version contains supplementary material available at https://doi. org/10.1186/s12889-021-10977-5.

Additional file 1. Cross-sectional Study STROBE Checklist.

Additional file 2. Survey Questionnaire.

Acknowledgements

Our appreciation goes out to the participants of this study.

\section{Authors' contributions}

AJR, HD, TA, CC, GM, BJ, SH, JG, SWB, and SB contributed to the conceptualization and editing of this article. BJ and SWB curated and prepared the data. AJR analyzed the dataset. AJR, HD, TA, and CC wrote the manuscript. AJR, HD, TA, CC, GM, BJ, SH, JG, SWB, and SB authors were involved in data interpretation and reviewed the manuscript. The authors read and approved the final manuscript.

\section{Funding}

This study did not receive funding. AJR was supported by the National Institute of Allergy and Infectious Diseases (grant T32Al102623). The sponsor had no role in study design, data collection and analysis, decision to publish, or preparation of the manuscript.

\section{Availability of data and materials}

The datasets used and/or analysed during the current study are available from the corresponding author on reasonable request.

\section{Declarations}

Ethics approval and consent to participate

The Johns Hopkins School of Public Health Institutional Review Board reviewed and approved this study (IRB \#00000287). All procedures performed in studies involving human participants were in accordance with the ethical standards of the Johns Hopkins School of Public Health

Institutional Review Board in Baltimore, Maryland and with the 1964 Helsinki declaration and its later amendments or comparable ethical standards. This article does not contain any studies with animals performed by any of the authors. Written informed consent was obtained from all individual participants included in the study.

\section{Consent for publication}

Written consent for publication was obtained from all individual participants included in the study.

\section{Competing interests}

We declare no competing interests.

\section{Author details}

1'Department of Epidemiology, Johns Hopkins School of Public Health, $615 \mathrm{~N}$ Wolfe St, Baltimore, MD 21205, USA. ${ }^{2}$ Department of Health, Policy, and Management, Johns Hopkins School of Public Health, Baltimore, MD, USA. ${ }^{3}$ School of Law and School of Criminology and Criminal Justice, Northeastern University, Boston, MA, USA. ${ }^{4}$ amfAR, The Foundation of AIDS Research, Washington, DC, USA. ${ }^{5}$ Hornet, San Francisco, CA, USA. ${ }^{6}$ Department of Health, Behavior, and Society, Johns Hopkins School of Public Health, Baltimore, MD, USA. 'Department of International Health, Johns Hopkins School of Public Health, Baltimore, MD, USA.

Received: 8 January 2021 Accepted: 29 April 2021

Published online: 12 May 2021

\section{References}

1. Dong E, Du H, Gardner L. An interactive web-based dashboard to track COVID-19 in real time. Lancet Infect Dis. 2020;20(5):533-4. https://doi.org/1 0.1016/S1473-3099(20)30120-1.

2. Zheng $Q$, Jones FK, Leavitt SV, Ung L, Labrique AB, Peters DH, et al. HITCOVID, a global database tracking public health interventions to COVID-19. Sci Data. 2020;7(1):1-8 
3. Chenneville T, Gabbidon K, Hanson P, Holyfield C. The impact of COVID-19 on HIV treatment and research: a call to action. Int J Environ Res Public Health. 2020;17(12):4548. https://doi.org/10.3390/ijerph17124548.

4. Wang Y, Pan B, Liu Y, Wilson A, Ou J, Chen R. Health care and mental health challenges for transgender individuals during the COVID-19 pandemic. Lancet Diabet Endocrinol. 2020;8(7):564-5. https://doi.org/10.1016/S22138587(20)30182-0.

5. Ridgway JP, Schmitt J, Friedman E, Taylor M, Devlin S, McNulty M, et al. HIV care continuum and COVID-19 outcomes among people living with HIV during the COVID-19 pandemic, Chicago, IL. AIDS Behav. 2020;1:2770-2.

6. Reisner SL, Poteat T, Keatley J, Cabral M, Mothopeng T, Dunham E, et al. Global health burden and needs of transgender populations: a review. Lancet. 2016;388(10042):412-36. https://doi.org/10.1016/S0140-6736(1 6)00684-X.

7. Poteat TC, Reisner SL, Miller M, Wirtz AL. Vulnerability to COVID-19-related harms among transgender women with and without HIV infection in the eastern and southern US. J Acquir Immune Defic Syndr. 2020;85(4):e67-9. https://doi.org/10.1097/QAl.0000000000002490.

8. Glick JL, Theall KP, Andrinopoulos KM, Kendall C. The role of discrimination in care postponement among trans-feminine individuals in the US National Transgender Discrimination Survey. LGBT Health. 2018;5(3):171-9. https://doi. org/10.1089/lgbt.2017.0093.

9. Casey LS, Reisner SL, Findling MG, Blendon RJ, Benson JM, Sayde JM, et al. Discrimination in the United States: experiences of lesbian, gay, bisexual, transgender, and queer Americans. Health Serv Res. 2019;54(S2):1454-66. https://doi.org/10.1111/1475-6773.13229.

10. Safer JD, Coleman E, Feldman J, Garofalo R, Hembree W, Radix A, et al. Barriers to health care for transgender individuals. Curr Opin Endocrinol Diabetes Obes. 2016;23(2):168.

11. Stroumsa D, Shires DA, Richardson CR, Jaffee KD, Woodford MR. Transphobia rather than education predicts provider knowledge of transgender health care. Med Educ. 2019;53(4):398-407. https://doi.org/1 0.1111/medu.13796.

12. Sevelius JM, Patouhas E, Keatley JG, Johnson MO. Barriers and facilitators to engagement and retention in care among transgender women living with human immunodeficiency virus. Ann Behav Med. 2014;47(1):5-16. https:// doi.org/10.1007/s12160-013-9565-8.

13. Mizuno $Y$, Beer L, Huang P, Frazier EL. Factors associated with antiretroviral therapy adherence among transgender women receiving HIV medical care in the United States. LGBT Health. 2017;4(3):181-7. https://doi.org/10.1089/ lgbt.2017.0003.

14. Lacombe-Duncan A, Bauer GR, Logie CH, Newman PA, Shokoohi M, Kay ES, et al. The HIV care cascade among transgender women with HIV in Canada: a mixed-methods study. AIDS Patient Care STDs. 2019;33(7):308-22. https:// doi.org/10.1089/apc.2019.0013.

15. Gaillard J-C, Gorman-Murray A, Fordham M. Sexual and gender minorities in disaster. Gender, Place Culture. 2017;(24:1):18-26. https://doi.org/10.1080/ 0966369X.2016.1263438.

16. Gibb JK, DuBois LZ, Williams S, McKerracher L, Juster RP, Fields J. Sexual and gender minority health vulnerabilities during the COVID-19 health crisis. Am J Hum Biol. 2020;32(5):e23499. https://doi.org/10.1002/ajhb.23499.

17. Zheng Z, Peng F, Xu B, Zhao J, Liu H, Peng J, et al. Risk factors of critical \& mortal COVID-19 cases: a systematic literature review and meta-analysis. J Infect. 2020;81(2):e16-25. https://doi.org/10.1016/j.jinf.2020.04.021.

18. Wolff D, Nee S, Hickey NS, Marschollek M. Risk factors for Covid-19 severity and fatality: a structured literature review. Infection. 2020:49:1-14.

19. D'Antiga L. Coronaviruses and immunosuppressed patients: the facts during the third epidemic. Liver Transpl. 2020;26(6):832-4. https://doi.org/10.1002/ It.25756.

20. Ochi S, Hodgson S, Landeg O, Mayner L, Murray V. Disaster-driven evacuation and medication loss: a systematic literature review. PLoS Curr. 2014;6(1):1-27. https://doi.org/10.1371/currents.dis.fa417630b566a 0c7dfdbf945910edd96.

21. Scheim Al, Appenroth MN, Beckham SW, Goldstein Z, Grinspan MC, Keatley JG, et al. Transgender HIV research: nothing about us without us. Lancet HIV. 2019;6(9):e566-7. https://doi.org/10.1016/S2352-3018(19)30269-3.

22. Poteat T, Scheim A, Xavier J, Reisner S, Baral S. Global epidemiology of HIV infection and related syndemics affecting transgender people. J Acquir Immune Defic Syndr. 2016;72(Suppl 3):S210.
23. Edelman EJ, Aoun-Barakat L, Villanueva M, Friedland G. Confronting another pandemic: lessons from HIV can inform our COVID-19 response. AIDS Behav. 2020;1:1977-9.

24. Santos G-M, Ackerman B, Rao A, Wallach S, Ayala G, Lamontage E, et al. Economic, mental health, HIV prevention and HIV treatment impacts of COVID-19 and the COVID-19 response on a global sample of Cisgender gay men and other men who have sex with men. AIDS Behav. 2020;25(2): 31121.

25. World Health Organization: Definition of regional groupings. 2017.

26. Tibshirani R. Regression shrinkage and selection via the lasso. J R Stat Soc Ser B Methodol. 1996;58(1):267-88.

27. Parra-Frutos I. Controlling the type I error rate by using the nonparametric bootstrap when comparing means. Br J Math Stat Psychol. 2014;67(1):11732. https://doi.org/10.1111/bmsp.12011.

28. Restar A, Jin H, Operario D. Gender-inclusive and gender-specific approaches in trans health research. Transgender Health. 2020. https://doi. org/10.1089/trgh.2020.0054.

29. Nicola M, Alsafi Z, Sohrabi C, Kerwan A, Al-Jabir A, losifidis C, et al. The socio-economic implications of the coronavirus pandemic (COVID-19): A review. Int J Surg. 2020;78:185.

30. Chetty R, Friedman JN, Hendren N, Stepner M, The Opportunity Insights Team. How did COVID-19 and stabilization policies affect spending and employment? A new real-time economic tracker based on private sector data. Nat Bur Econ Res. 2020;1 (1):27431-27534.

31. Choi E, Wong J, Fong D. The use of social networking applications of smartphone and associated sexual risks in lesbian, gay, bisexual, and transgender populations: a systematic review. AIDS Care. 2017;29(2):145-55. https://doi.org/10.1080/09540121.2016.1211606.

32. Roberts TK, Fantz CR. Barriers to quality health care for the transgender population. Clin Biochem. 2014;47(10-11):983-7. https://doi.org/10.1016/j. clinbiochem.2014.02.009.

33. Operario D, Nemoto T. On being transnational and transgender: human rights and public health considerations. Am J Pub Health. 2017;107(10): 1537-8.

34. Bowleg L. We're not all in this together: on COVID-19, intersectionality, and structural inequality. Am J Pub Health. 2020;110(7):917-21.

\section{Publisher's Note}

Springer Nature remains neutral with regard to jurisdictional claims in published maps and institutional affiliations.
Ready to submit your research? Choose BMC and benefit from:

- fast, convenient online submission

- thorough peer review by experienced researchers in your field

- rapid publication on acceptance

- support for research data, including large and complex data types

- gold Open Access which fosters wider collaboration and increased citations

- maximum visibility for your research: over $100 \mathrm{M}$ website views per year

At BMC, research is always in progress.

Learn more biomedcentral.com/submissions 